\title{
Technology and Developing Trends of Automatic Catwalk in China's Drilling Rigs
}

\author{
Nilievna Nkanza ${ }^{1}$, Feng Ding ${ }^{1,2,3}$, Sun Qiaolei ${ }^{1,2,3}$ Tu Yiliu $^{1}$ \\ ${ }^{1}$ School of Mechanical Engineering, Yangtze University, Jingzhou, Hubei, 434023, China \\ ${ }^{2}$ Hubei Engineering Research Center for Oil \& Gas Drilling and Completion Tools, Jingzhou, Hubei, \\ 434023, China \\ ${ }^{3}$ Hubei Cooperative Innovation Centers of Unconventional Oil and Gas, Wuhan 430100, China
}

\begin{abstract}
:
The Improvement of automation technology and its application in drilling rig have increased the drilling rig safety and efficiency. The petroleum drilling rig in China has been increasing as China is the fourth-leading oil producer in the oil and gas industry. However, there is a low percentage of automation equipment and the automatic catwalk still remains at the traditional stage compared to other countries. This paper introduced the present situation of the domestic well drilling rig, automatic catwalk technologies and the development trend is summarized.
\end{abstract}

Keywords: Automatic Catwalk, Automation Technology, Drilling Rig, Development Trend.

\section{Introduction}

Well Drilling operation is one of the most costly and risky activities in oil and gas reservoir exploration and field development. A Part of this high cost is related to tubular transportation and handling operation. The management of the column pipe plays an important role in improving the drilling performance. In fact, the transportation of drill pipe, drill collar, and casing on the drilling rig are dangerous, can put the worker's safety and the entire drilling operation at risk this is Due to the fact that the tubular may be thousands of feet long and heavy, a mishandling of a single load may cause severe injury on the well site. Since 1956, the first set of mechanized drill pipe handling system was installed in CUSS-1 drilling ship , the development of mechanization and automation on drilling rig has brought the used of state-of-the-art automated full-sized equipment [1] such as Iron Roughneck, top drive assembly, any kinds of pipe conveying equipment such as automatic Catwalk has been designed to transport pipe column from the pipe rack to the rig floor. This equipment overcomes some of the foregoing difficulties while providing more advantageous overall [2] such as
- Prevent physical injuries and increase the human safety and eliminates the necessity for the handling of tubular during pick up and lay down operations.

- Improve process by more precise control

- Operate in any drilling rigs due to the flexibility and the mobility

- Reduces the labor cost and improves the economies profit

- Deliver any tools needed on the rig floor such as drill bit, bottom-hole assembly BHA etc...

*Corresponding author.

E-mail address: fengd0861@163.com (D. Feng)

In order to improve the automation of drilling rig and meet the needs of safety and efficiency, the automatic catwalk machine has become a new direction in the research of the petroleum equipment industry. However, there is still another challenge while the oil and gas industry is developing drilling automation technologies, the used of automated equipment such automatic catwalk in China oil rigs still suffering from a shortage [3]. This is because; the automation is seen as an ultimate game-changer, and therefore an area of competitive differentiation. 


\section{Current Status of the Domestic Drilling Rig}

The Traditional catwalk is still the main equipment used in a domestic drilling rig for drill-pipes transportation and handling operation, it is composed of a strip truss structure and a ramp [4]. The ramp, the strip truss, and the drill rod are all independent components, they need to be transported separately, and it is necessary to assemble and disassemble [5]. More than two workers are required for the operation, for example, tubular are manually processing from the ground to the rig floor using the following methods:

1. Workers pushed the tubular from the horizontal pipe rack to the catwalk [5]. Then from the top floor, the Floorman is standing next to catwalk inside the danger zone and uses hoisting rigging method to lift the pipe along the slope from the catwalk base to the rig floor. On the top floor, The Tubular stops on catwalk v-door without supports, two or three workers are required to hold by single joint elevators while installing safety pin in SJE at top of V-door and slowly moved to the derrick arm to allow pipe roughness, as shown in figure 1.

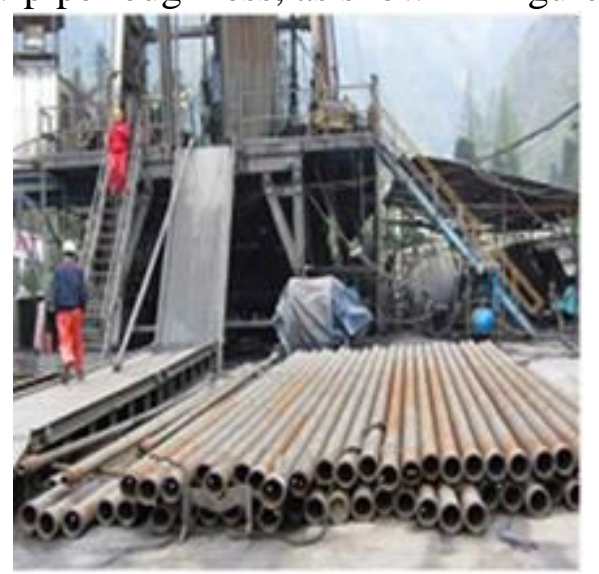

Figure 1: The worker pushes a string along the catwalk using pneumatic winch steel rope.

2. In order to return the tubular from the drilling floor to the horizontal pipe rack store, the workers use two pneumatics winch wire rope to hang the top of the tubular first and then, hooks the bottom with a pneumatic winch on the slope sliding back into the catwalk base. An unsafe Laydown Bucket Attachment is observed as shown in figure 2.

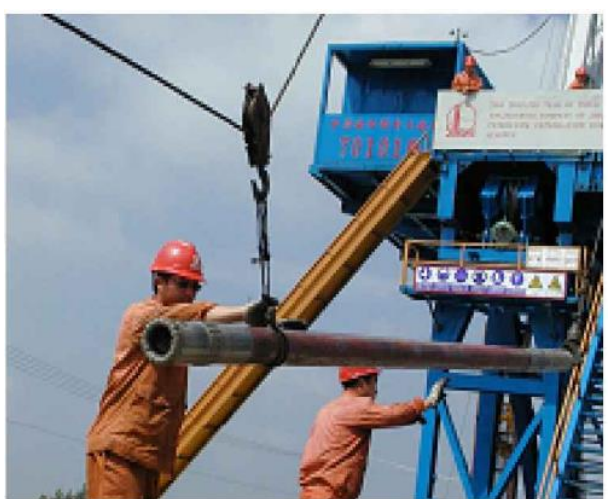

Figure 2: The Workers Use the Pneumatic Winch

Steel Wire Rope and Hook

However, these techniques are inadequate and improper, increase the labor cost, increases the danger of the well site, and the efficiency of the drilling operation is very low.

In addition, the report from the British oil company showed that $77 \%$ damage was caused by the operation of the pipe column in oil drilling operations [6], as shown in Figure 3.

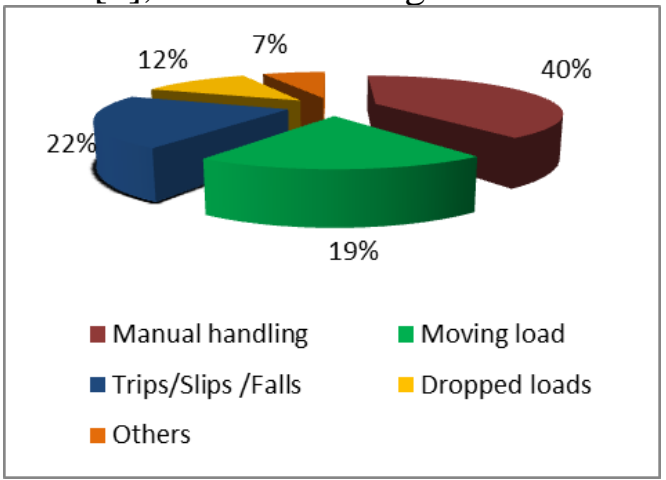

Figure 3: HSE Health and Safety Executive Data Report from the British Petroleum Company

\section{Automatic Catwalk Technology}

Automatic catwalk device handles tubular from the pipe rack to the rig floor and from the floor to the level on the pipe rack. The automatic catwalk conveys tubular such as drill pipe joint (including single, double or triple drill pipe joint), drill collars, casing and tools such as bottom-hole assemblies (BHA), drill bit etc. It capable to accommodate and deliver a single load in a short range of time and pipe joint is usually placed near the wellbore to minimize the time of the transportation. The automatic catwalk control system is equipped with an onboard Programmable Logic Controller (PLC), the position-controller, regulators and feedback signal [7]. This allows the operator to have a full control over the catwalk machine and solve the problems of pipe string transportation such as heavy labor intensity and low efficiency [8]. A feed mechanism or a kick out unit is located along the 
catwalk base to feed a single joint onto and out of the catwalk machine at a time.

Today, foreign advanced drilling platforms are equipped with advanced semi-automatic equipment such as an automatic catwalk. Their emission systems have been widely studied and applied abroad in the United States, Germany, and Russia. According to its working principle and mechanical design structure, automatic catwalk machine can be divided into three common kinds: fixed automatic catwalk, lifting automatic catwalk, and automatic mechanical arm processing.

\subsection{Fixed automatic catwalk}

The Fixed automatic catwalk is described by a fixed relationship between the floor and ramp. The tubular movement is driven by a special tool that pushes the pipe along the $\mathrm{V}$-shaped groove from the base of the catwalk to the drilling platform. Its structure is relatively simple, easy to disassemble, the cost of maintenance is low and the workload of the whole processing is very small. However, the safety of the pipe joint is very low because there is a large friction between the $\mathrm{V}$-shaped slope and pipe joint during the pushing. The fixed automatic catwalk is usually applied on a small drilling rig. Based on the survey of drilling rig technology abroad, the fixed automatic catwalk can be found and manufactured in the United States, North rig Technology Company [9]

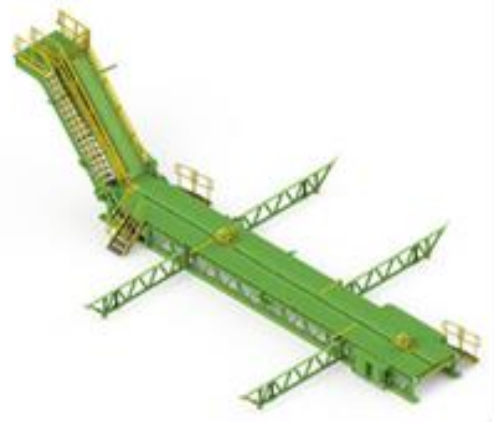

Figure 4: C16 Power Catwalk, Hunterwood Technologies

\subsection{The lifting automatic catwalk}

The main features are catwalk base assembly or catwalk desk located horizontally near the pipe crack, a hydraulic winch, a transfer arm and a supporting Arm, ramp assembly [10] a fully automated control system. However, the use of ramp assembly depends on the lifting mechanism. Its lift operation is powered either by hydraulic winches or hydraulic cylinder [11]. During the migration operation of tubular, tubular loaded into the $\mathrm{V}$ slot or transfer arm, an anti-fall mechanism is mounted on to prevent the pipe from fall over while the transfer arm rose from the catwalk to the drill floor by mean of a wire rope or hydraulic cylinder and finally by a special pusher assembly, the tubular is pushed to a position relative to the wellhead [12]. The lifting operation is more commonly used in land rigs, offshore oil rigs and it is known for its smooth operation, its safety system operation and its flexibility but the lifting process is discontinuous and the efficiency is relatively low[13]. The lifting automatic catwalk has received a great attention from many foreign companies, such as, CANRIG Company, which produces POWER CATWALK automatic catwalk [14].

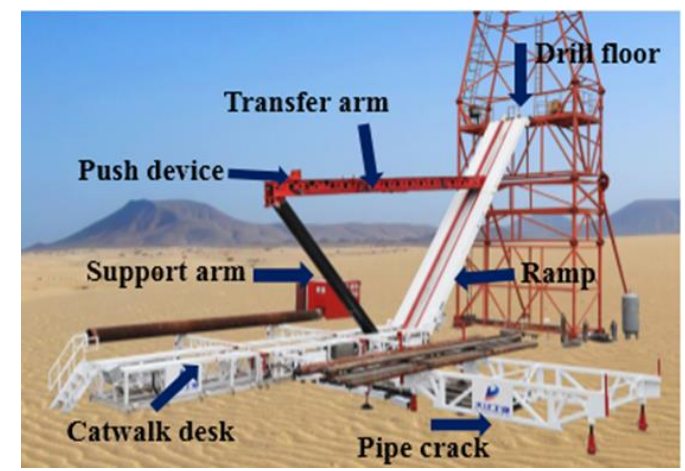

Figure 5: Automatic Lifting Catwalk Structure

\subsection{Automatic Mechanical Arm processing}

It is a combination of a Joint hoisting machine system, a catwalk desk or a dynamic catwalk, and a vertical arm pipe holding system. Its main feature is the direct realization of drilling tools, which generally canceled the traditional catwalk assembly and ramp need. The Joint hoisting machine system [15] is automatically used as an arm capable of transporting pipe to the from a horizontal pipe storage to the catwalk desk or a dynamic catwalk position location, a push device assembly which allowed the pipe joint to be moved horizontally near the dynamic mouse hole, a vertical arm holding system mounted the drill floor, operates in 90-degree rotation mode to complete the pipe joint migration to the mouse hole for pipe roughneck. Its operations are fully automated and no need for manual intervention in operation and the worker usually placed on drillers' cabin control. The automatic mechanical arm processing is known for its high speed of operation. However, between the platform and the pipe rack, the distance is very small. It is often used in an offshore drilling platform. The automatic mechanical arm can be found in Aker Kvaerner MH Company such as the Eagle/Eagle Light horizontal to vertical (HTV) 
device which is fully automated and can be operated either from a separate control panel or from the driller's cabin its motion is described by its robotic arm [16]

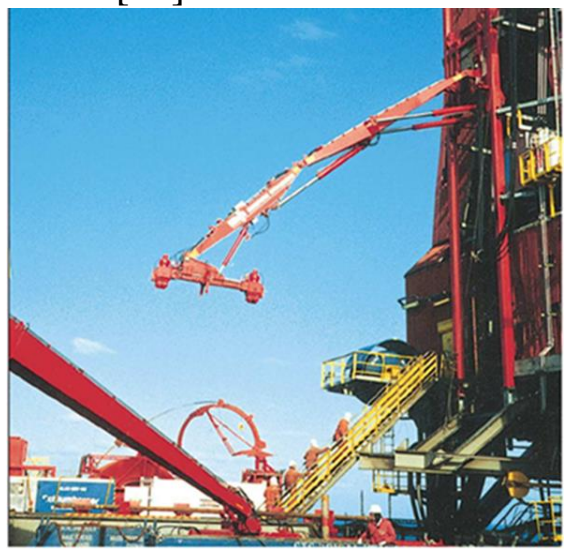

(HTV) equipment from Aker Kvaerner MH Company, Norway rig

Figure 6: Eagle/Eagle Light horizontal to vertical
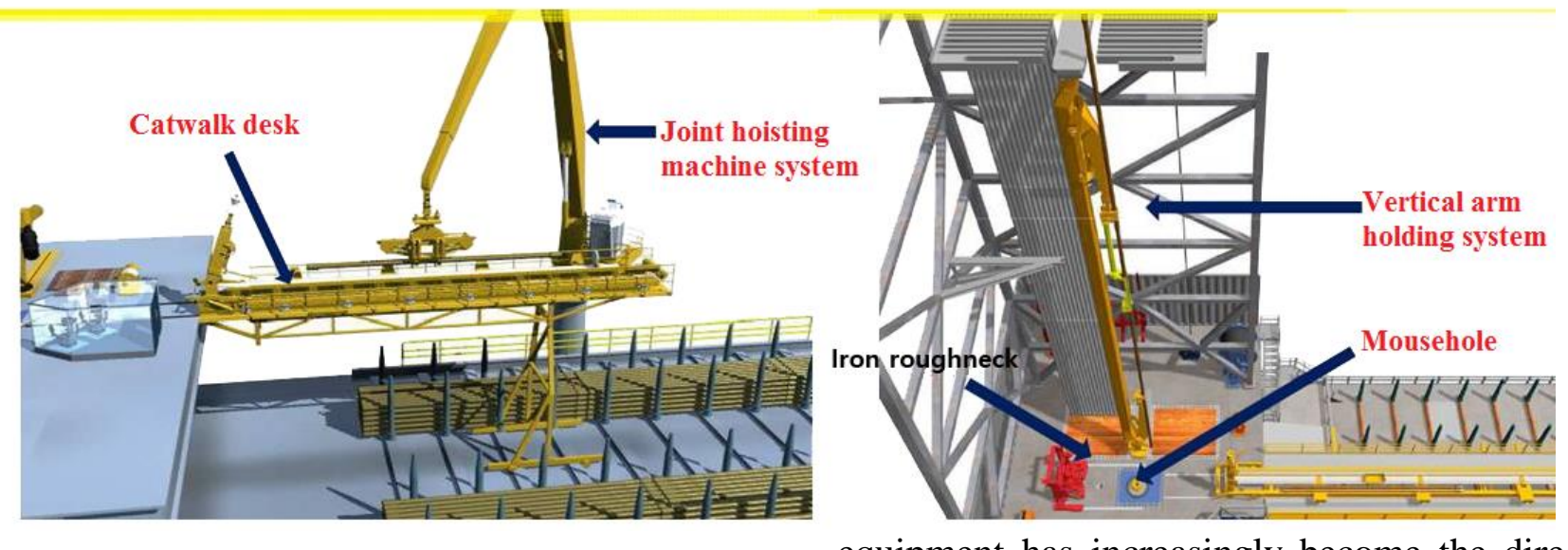

equipment has increasingly become the director of the development of oil drilling companies. At the

Figure 7: Automatic Mechanical Arm Processing Offshore Installation

In Germany, The Herrenknecht Vertical produces the Herrick Herrenknecht TI-350 drilling pipe conveying device apply in the Terra Invader 350 deep drilling rig [17]. It able to convey $2 \frac{1}{2}$ to $24 \frac{\mathrm{a}}{\mathrm{g}}$ inch drill Pipe diameter. As shown in figure 8.

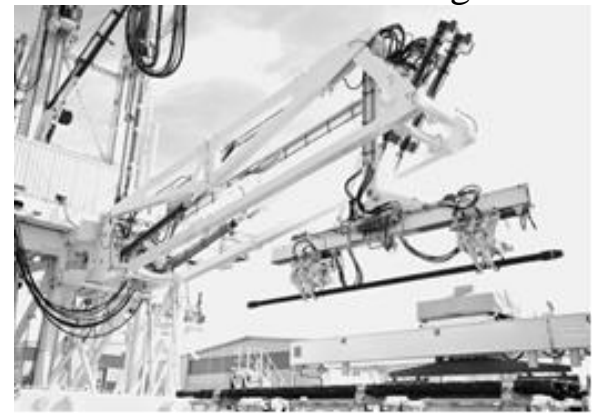

Figure 8: Pipe Handle System, Herrenknecht TI-350

\section{DEVELOPMENT TREND}

Recently, with the saturation of the land oil drilling equipment market in China, offshore drilling same time, with the increase of well depth, the growing demand in the drilling site for more and more string leads to a poor efficiency in the drilling operation but the automatic catwalk development in the drilling will help to relieve this situation. Many giant contractors are improving their own automatic catwalk technologies in the face of extremely Workplace Health and Safety Hazards and as well as an extreme shortage of string in the drilling site. The challenges of the column pipe management in drilling site mainly involve low insurance of well site safety, low drilling efficiency, and high labor cost. New demands are proposed for the automatic catwalk to overcome the challenges. The development trends of Automatic catwalk are listed as follows

1.The New automatic catwalk will contain a strong transport capacity tool, a fast conveyor mechanism; for example, the automatic catwalk can be combined with an automatic drilling rod, an automatic discharge device of drilling tools, a pneumatic slip, and the iron drillers.

2.The newest generation of automatic catwalk will not only increase operating efficiency but 
also improve rig floor safety and extend pipe longevity by reducing handling damage.

3.In the nearest future with the development of offshore drilling to deep well and even ultra-deep a complete product catwalk light structure easy to be transported from rig to rig, quick installation and easy maintenance.

4. New automatic catwalk main component will be made with high-nickel-based mild steel, which reduces the influence of cold weather on impact ductility,

5. A Fully automated and fast processing system will be implemented in both land and offshore rig and the technology can be widely used in the offshore drilling platform.

\section{Acknowledgment}

This work was supported by the National Science and Technology Major Project of China under Grant No. 2016ZX05038-002-LH001, the National Natural Science Foundation of China under Grant No. 51275057 and 51704034.

\section{CONCLUSION}

The improvement of drilling operations has an important impact on reducing the cost of drilling operations, improving the production time of oil, and the safety of the workers. Based on the understanding of automatic catwalk technologies, automatic catwalk has been used to improve and speed up the performance of string management activities, improving the efficiency of the drilling operation and implement the concept of safety, health, and environmental protection. Development trend of automatic catwalk can be predictable base on the fast development of automated drilling technologies. However, in China's oil drilling platform, a low percentage of automation equipment and automatic catwalk still remain at the traditional stage compared with other countries. Fixed automatic Catwalk suitable only suitable for small drilling floor below $2000 \mathrm{~m}$ height. The automatic mechanical arm processing is highly automated, but it is not easy to maintain, very expensive to purchase, complex installation, and it is not suitable for frequent disassembly and transportation. On the other hand, automatic lifting catwalk machine is widely applied, but its lifting process is discontinuous, its structure is large and heavy, around 70-90\%, the total weight of a machine is due to the weight structure. In order to further improve the efficiency of the system, further research is needed.

\section{References}

[1] David Reid Varco International Inc., "The Development of Automated Drilling Rigs", ADC/SPE Drilling Conference, pp. 695-710,1998

[2] Ren De Yong, Liu Yanshu, Wang Yuanzhong, et al. "Research on the Mechanical Properties of Automatic Catwalk Hoisting Wire Rope". Mechanical research and application, 27(4), pp.132,2014

[3] Youhong Sun, Feiyu Zhang, et al. "Application of "Crust 1" 10k Ultra-Deep Scientific Drilling Rig in Songliao Basin Drilling Project (CCSD-SKII)", Journal of Petroleum Science and Engineering, 145, pp. 222-229,2016

[4] Fu Yanxia, Wan Guangwei, et al. "Development and Application of Automatic Pipe Lifting System", Petroleum Machinery, 44 (08), pp.15-19,2016

[5] Sun Qiao Lei, Xu Jun, Wang Chieh, et al. "Dynamic Modeling and Analysis. Power Cat Track Lifting Process", Mechanics, and Practice, 39 (03), pp.260-267, 2017

[6] "Drilling Accidents Fall 19\% in '98", IADC, September/October

1999 , http://www.iadc.org/dcpi/dc-sepoct99/s-asp\%20 99.pdf

[7] Trond Loeying, Cameron, "Automated catwalk machine for Lang rig", Society of Petroleum Engineers, Abu Dhabi International Petroleum Exhibition \& Conference, pp. 2-7,2017

[8] Zhang Qiang, Lin Kang, He Qing, et al. "Development of horizontal power cat road automatic control system based on PLC" Electrical automation, 39 (03), pp.113-115,2017

[9] ZHAO Shu-Lan, LI Wenbiao, et al. "Technology and Developing Trend of Power Catwalk At Home And Abroad", Oil Field Equipment, 39(2), pp.13 - 15,2010

[10]Wang Jie, Quian Liqin, Chen Xinlong, et al. "Dynamic Model and Analysis of a Lifting System of Automatic Catwalk", Chinese Journal of Engineering Design, 23(5),pp.438-443,2016

[11]Sun Qiaolei. "Design and Theoretical Research on Drilling String Conveying Equipment". Master thesis, School of Mechanical Engineering, Yangtze University,2016

[12]Song Jie, Yu Ping, Zhao Nan. "Optimization Design and Simulation Analysis of Full Hydraulic Automatic Catwalk Falling Mechanism”, Oil Field Machinery, 47 (03), pp.33-38,2018

[13]Kang Sijie, Yu Ping, et al. "Research on Control Strategy of Full Hydraulic Automatic Cat Lift 
System”. Machine Tool and Hydraulic, 44 (03), pp.102-105, 2016.

[14]CANRIG Drilling Technology LTD Automated Power Catwalk Brochure, available: http://www.canrigdrillingtechnology.com

[15]David Harris, Egill Abrahamsen, "the Mechanization of the Tubular Running and Handling Process", IADC/SPE, Asia Pacific Drilling Technology Conference, pp.233-235, 1996.

[16]AkerKvaerner MH General Catalogue,2006, available:

http://img2.eworldship.com/2012/0904/201209 04033830863.pdf

[17]Herrenknecht VerticaL GMBH, Pipe Handling Modernization Package, available: https://www.herrenknecht-vertical.com/ 